\title{
Discrimination learning in the T-maze based on the secondary reinforcing effects of shock termination
}

\author{
W. P. BELLINGHAM, L. H. STORLIEN, and R. J. STEBULIS \\ The Australian National University, Canberra, A.C.T. Australia, 2600
}

\begin{abstract}
The reinforcing effect of a light paired with shock termination was demonstrated. Albino rats were trained in a fear conditioning paradigm with a tone acting as a warning stimulus and light signaling the termination of varying shock durations. The light later provided the reinforcement for discrimination learning in a T-maze.
\end{abstract}

In spite of a number of attempts to demonstrate secondary reinforcement effects attributable to a stimulus signaling shock termination, there are few convincing studies (See reviews by Beck, 1961; Siegel \& Milby, 1969.) Only one study (Murray \& Strandberg, 1965) appears to have provided reasonably convincing evidence. However, even this study has been criticized on the grounds that the results can be attributed to elicitation rather than reinforcement. Murray and Strandberg (1965) tested for the reinforcing effects of the shock termination signal in a straight runway using resistance to extinction as the strength measure. Due to the fact that their ITI was under $1 \mathrm{~min}$ it could be argued that the prolonged extinction of the experimental group was due to the energizing effect of the stimulus rather than reinforcement. One aspect of the study lends some credence to this interpretation. The stimulus signaling shock termination was not established as a discriminative stimulus, a manipulation considered by some to be essential (e.g., Keller \& Schoenfeld, 1950). That is, a barpress terminated the shock and the critical stimulus followed.

The following study is an attempt to provide support for the reinforcing value of a stimulus signaling shock termination under conditions where: (a) the stimulus is discriminative and informative (Egger \& Miller, 1962), (b) motivation is maintained in the test phase (Mowrer \& Aiken, 1954), and (c) the measure of secondary reinforcement is based on the acquisition of a new response.

\section{METHOD}

\section{Subjects}

The subjects were 20 naive male albino rats approximately 100 days old from the breeding colony of the John Curtin School of Medical Research (Canberra, Australia). They were housed individually and given ad lib access to food and water.

\section{Apparatus}

A T-maze was used in which the startbox also operated as the training chamber. The start and goal chambers were $30 \times 30 \times 19 \mathrm{~cm}$. The distance from the startbox door to the

This paper is sponsored by F. A. Logan who takes full editorial responsibility for it. apex of a wedge shaped block (base $20 \mathrm{~cm}$, sides $26 \mathrm{~cm}$ ) was $60 \mathrm{~cm}$. The apex of the wedge was centered in the runway and acted as the choice point. The right goalbox face and the right side of the wedge were painted white. The left side was similarly painted matte black. The exit from the start-training chamber and entrances to the goalboxes were $10 \times 7 \mathrm{~cm}$. Two lights $9 \mathrm{~cm}$ above the grid floor and $15 \mathrm{~cm}$ apart were located on the wall opposite the exit door of the training chamber. Lights were comparably placed in the goalboxes. The lights were $5-\mathrm{W}$ and signaled shock termination. A tone provided the shock onset warning stimulus. It was delivered through the side of the training chamber and was $1000-\mathrm{Hz}$ at approximately $75 \mathrm{~dB}$. Electric shock was delivered by a BRS Model 2902 shocker-scrambler through $2-\mathrm{mm}$ diam stainless steel grids at $130 \mathrm{~V}$. During training all stimulus presentations and ITIs were programmed by an eight-channel paper tape reader and Digital Corporation K-logic modules. The test phase was hand timed and operated.

\section{Procedure}

During pretraining all the subjects were handled for approximately $10 \mathrm{~min}$ a day for 5 days. On the following 2 days groups of four subjects were allowed free exploration of the maze for $1 \mathrm{~h}$ with all doors open. Training for experimental group $(n=10)$ consisted of 50 trials divided into 10 shocks each of 2-, 5-, 9-, 13-, and 21-sec durations. The durations were randomly ordered around a mean ITI of $30 \mathrm{sec}$ with a range of 10-50 sec. Not more than two shocks of the same duration were allowed in sequence. All shocks were preceded by a warning tone of $5 \mathrm{sec}$ that terminated with shock onset. The lights signaling shock termination were of 2-sec duration and came on $1 \mathrm{sec}$ prior to the end of shock. A control group $(n=10)$ was treated identically except that $2 \mathrm{sec}$ of lights were never paired with shock or within $5 \mathrm{sec}$ of its onset or offset.

Testing followed training within $10 \mathrm{~min}$. There were two nonreinforced pretest trials followed immediately by 20 test runs. In the first pretest the warning tone was presented and the exit from the training chamber opened simultaneously. The subject was permitted entry into either goalbox. As soon as the hind quarters passed the entrance to the goal chamber the door was closed and the tone terminated. The subject was removed after $10 \mathrm{sec}$ and placed in his home cage for a minimum of 3 and up to $10 \mathrm{~min}$. The mean ITI during the test period was $6 \mathrm{~min}$. The subject was then removed from his home cage, placed again in the start-training chamber with the exit door closed, and after $15-30 \mathrm{sec}$ the warning tone sounded. In the second pretest trial the subject was forced to the opposite side by simply closing off the appropriate goal chamber door. In all subsequent test trials the procedure was the same except that the subject was always allowed free choice and reinforced with $5 \mathrm{sec}$ of flashing light following any choice opposite the initial pretest preference. The lights were never delivered until the subject's hind quarters 


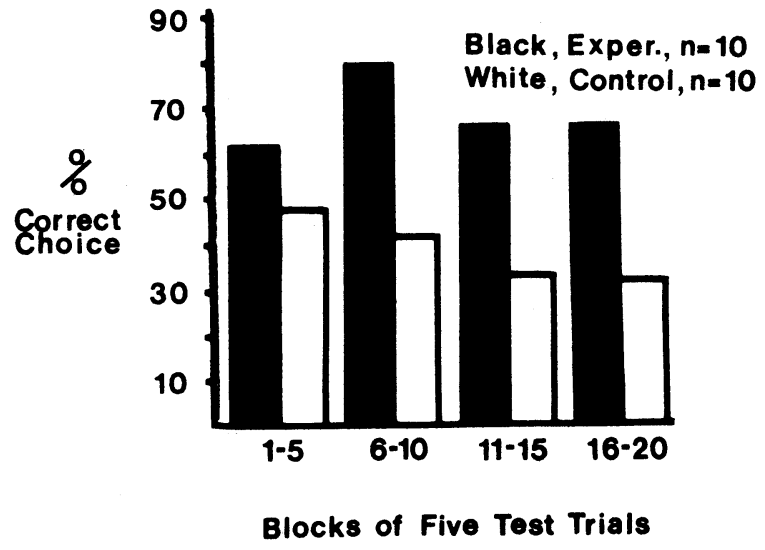

Figure 1. Percent correct choice of the light reinforced goalbox for the experimental and control subjects in blocks of five test trials.

passed the entrance. Their onset occurred concurrently with door closure and offset of the warning tone. The control group was treated in an identical fashion.

\section{RESULTS AND DISCUSSION}

Figure 1 shows the distribution of choices for the light reinforced goal for the two groups. They differed significantly on a two-tailed test based on 20 trial means $(\mathrm{t}=2.56, \mathrm{df}=18, \mathrm{p}<.02)$. The result indicates that a stimulus signaling shock termination acquires secondary reinforcing properties strong enough to support new learning under the present experimental conditions.

It seems highly unlikely that the result can be attributed to elicitation effects of either an energizing or associative variety (cf., Siegel \& Milby, 1969). Any energizing effects due to the reinforcing stimulus are irrelevant, since correct choice rather than running speed was the test measure. Associative elicitation seems unlikely for several reasons. The test trials required the learning of new responses, thereby eliminating response generalization, the reinforcing stimulus was contingent on the subject entering the goal chamber and therefore could not adventitiously elicit the response, and the test trials were widely spaced to minimize trial to trial carryover.

The authors prefer to attribute this positive result to the fact that the critical stimulus was informative and highly discriminative with respect to shock offset. Egger and Miller (1962) have show that informative stimuli were more powerful secondary reinforcers than noninformative (or informationally redundant) stimuli. This is a procedural point apparently not appreciated in a number of studies (e.g., Kinsman \& Bixenstine, 1968; Murray \& Strandberg, 1965; Wagman \& Allen, 1964). In addition, fear motivation was maintained in the test phase. Secondary reinforcing effects based on appetitive drives are reduced in the absence of the appropriate drive (Schlosberg \& Pratt, 1956). It is reasonable to expect that the same would be true in the aversive case.

\section{REFERENCES}

Beck, R. C. On secondary reinforcement and shock termination. Psy chological Bulletin, 1961, 58, 24-45.

Egger, M. D., \& Miller, N. E. Secondary reinforcement in rats as a function of information value and reliability of the stimulus. Journal of Experimental Psychology, 1962, 64, 97-104.

Keller, F. S., \& Schoenfeld, W. N. Principles of Psychology. New York: Appleton-Century-Crofts, 1950

Kinsman, R. A., \& Bixenstine, V. E. Secondary reinforcement and shock termination. Journal of Experimental Psychology. $1968,76,62-68$.

Mowrer, O. H., \& Aiken, E. G. Contiguity vs. drive-reduction in conditioned fear: Temporal variations in conditioned and unconditioned stimulus. American Journal of Psychology, 1954, 67, 26-38.

Murray, A. K., \& Strandberg, J. M. Development of a conditioned positive reinforcer through removal of an aversive stimulus. Joumal of Comparative and Physiological Psy chology, 1965, 60, 281-283.

Schlosberg, H., \& Pratt, C. H. The secondary reward value of food for hungry and satiated rats. Journal of Comparative and Physiological Psychology, 1956, 49, 149-152.

Siegel, P. S., \& Milby, J. B., Jr. Secondary reinforcement in relation to shock termination: Second chapter. Psychological Bulletin, 1969, 72, 146-156.

Wagman, W., \& Allen, J. D. The development of a conditioned positive reinforcer based upon the termination of shock Psy chonomic Science, 1964, 1, 363-364.

(Received for publication December 9, 1974.) 